\title{
MODELING OF PARTIAL OXIDATION OF METHANE IN A MEMBRANE REACTOR
}

\author{
F. A. N. Fernandes, \\ C. P. Souza ${ }^{b}$ \\ and J. F. Sousa ${ }^{b}$ \\ ${ }^{a}$ Universidade Federal do Ceará \\ Departamento de Engenharia Química \\ Campus do Pici, Bloco 709 \\ 60455-760 Fortaleza, CE, Brasil \\ fabiano@efftech.eng.br \\ ${ }^{\mathrm{b}}$ Universidade Federal do Rio Grande do Norte \\ Departamento de Engenharia Química \\ Campus Universitário \\ Natal, RN, Brasil \\ coefficient of component $i$
}

\begin{abstract}
Partial oxidation of methane is one of the most important chemical processes for the production of syngas. In recent years, the abundant availability of natural gas and the increasing demand of hydrogen have led to high interest to further develop this process increasing the yield of syngas. In this work the partial oxidation of methane was studied from a modeling point of view in a membrane reactor and in a conventional reactor. A mathematical model of a membrane reactor used for partial oxidation of methane, assuming steadystate conditions, was developed to simulate and compare the maximum yields and operating conditions in the reactor with that in a conventional reactor. Simulation results show that different parameters affect methane conversion and $\mathrm{H}_{2} / \mathrm{CO}$ ratio, such as temperature, operating conditions, and membrane parameters such as membrane permeance. In a membrane reactor an increase in the operating pressure corresponds to an increase in methane conversion, since allows for a greater partial pressure gradient between the reaction and permeate zone, thus contributing to shift the equilibrium towards the products. As such, the membrane reactors are a good alternative to produce syngas especially for GTL processes. Operating conditions can be set to control the $\mathrm{H}_{2} / \mathrm{CO}$ ratio to a desired value, and high conversions at mild temperatures can be achieved reducing capital and operational costs.
\end{abstract}

Keywords: membrane reactor, partial oxidation, methane, modeling

\section{NOMENCLATURE}

$A \quad$ tube sectional area $\left[\mathrm{m}^{2}\right]$

$C_{P} \quad$ heat capacity $[\mathrm{J} / \mathrm{g} . \mathrm{K}]$

$F_{i} \quad$ flow rate of component $i[\mathrm{~mol} / \mathrm{h}]$

$k_{i} \quad$ rate constant of reaction $i$

$K_{i} \quad$ equilibrium constant of reaction $i$ or adsorption

$P_{i} \quad$ partial pressure [atm]

$P_{T} \quad$ total pressure in the reaction zone [atm]

$R_{i} \quad$ rate of reaction $i\left[\mathrm{~mol} / \mathrm{h} . \mathrm{g}_{\text {cat }}\right]$

$r_{m} \quad$ radius of the membrane [m]

$r_{T} \quad$ radius of the reaction tube [m]

$T$ temperature [K]

$u_{s} \quad$ superficial velocity $[\mathrm{m} / \mathrm{h}]$

$z \quad$ distance from the inlet of the reaction tube $[\mathrm{m}]$

Greek symbols

$\rho_{b} \quad$ catalyst density $\left[\mathrm{g} / \mathrm{m}^{3}\right]$

\section{Superscripts}

$A Z \quad$ air flow zone

$R Z \quad$ reaction zone

\section{INTRODUCTION}

Partial oxidation of methane has attracted substantial interest over the years for the production of syngas and hydrogen. In recent years, the abundant availability of natural gas and the increasing demand of hydrogen have led to high interest to further develop this process increasing the yield of syngas.

The partial oxidation reaction has been extensively studied for the production of syngas (Ashcroft et al., 1990; Disanayake et al., 1991; Rajaput \& Prabhakar, 1992; Hickman \& Schmidt, 1993). Partial oxidation of methane involves one non-reversible reaction (methane combustion) and two reversible reactions (steam reforming and carbon dioxide reforming). Methane combustion is a very fast and highly exothermic reaction, which releases a great quantity of energy demanding a good temperature control as not to compromise the reactor and reaction tubes structure. So a membrane reactor offers the possibility of supplying oxygen for the reaction throughout the entire reactor length controlling the combustion reaction in the reactor and spreading the heat release throughout the reactor not only at its beginning.

The development of oxygen permeable membranes has opened up a new possibility to enhance the partial oxidation of methane process. New improvements are been done in membrane materials and structures, which supports the selective compound in porous alumina, porous ceramic substrate, and in nanostructured carbides, and several works suggests the oxygen-permeating dense membranes have potential applications in partial oxidation of methane (Balachandran et al., 1997; Tsai et al., 1997; Kao et al., 1997).

The modeling and simulation of catalytic membrane reactors for methane conversion to syngas has been done by some authors, specially on steam reforming of methane and oxidative coupling of methane (Shu et al., 1994; Wang and Lin, 1995; Kao et al., 1997; Assaf et al., 1998; Chen et al., 2003; Lin et al., 2003; Gallucci et al., 2004). Very few works have dealt with partial oxidation of methane in membrane reactors (Tsai et al., 1997; Jin et al., 2000) and none dealing with the production of syngas for gas-to-liquid (GTL) processes.

This work presents the mathematical modeling of a one-dimensional, isothermal membrane reactor operating at steady-state, comparing and discussing reactor and yield improvements. 


\section{Ciência/Science}

\section{MEMBRANE REACTOR}

In partial oxidation of methane, the catalytic fixedbed reactor is fed with a gas mixture of $\mathrm{CH}_{4}$ and $\mathrm{O}_{2}$. Commercial catalyst is composed of zirconium and platinum supported in alumina or nickel supported in alumina and the reactor is composed of vertical tubes (between 10 and 900 tubes inside the reactor) with internal diameters from 7 to $16 \mathrm{~cm}$ and lengths from 6 to $12 \mathrm{~m}$, inserted in a radiant furnace chamber. The feed temperature is about $800 \mathrm{C}$. The maximum temperature that the reactor can support is limited by the metallurgical limitations of the tubes, since at higher temperatures the metal tubes can creep under stress.

The membrane reactor configuration is quite simple and consists of an external steel tube (shell) with an inner membrane wall tube which contains the catalyst. Air flows in the outer tube and oxygen permeates to the inner tube through the membrane. Methane and optionally $\mathrm{O}_{2}$ are continuously fed into the catalytic zone. A scheme of the reactor and mathematical model is shown in Fig. 1.

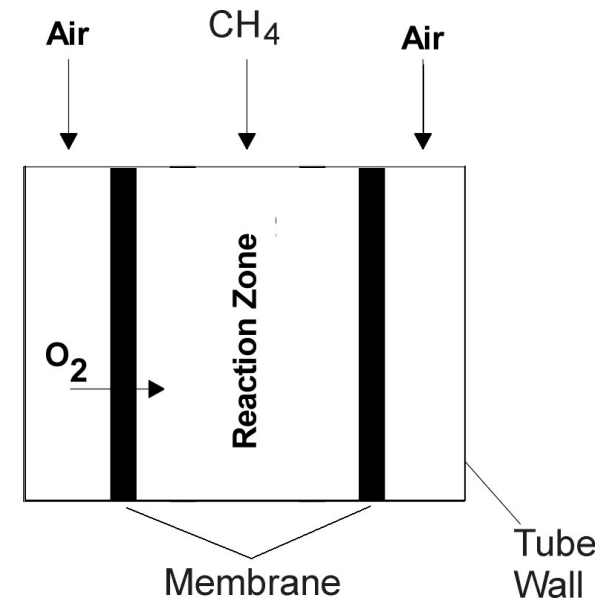

Figure 1. Scheme of the membrane reactor.

\section{MATHEMATICAL MODEL}

The basic assumptions made for the membrane reactor were:

- Steady-state operation;

- Isothermal conditions;

- $\quad$ Plug-flow on both reaction and air zones;

- No boundary layer on membrane surfaces;

- Intrinsic kinetics for methane combustion, carbon dioxide reforming and steam reforming reactions;

- $\quad$ Adsorption is the determinant step of the kinetic process (Xu \& Froment, 1989);

- The catalyst active sites have different adsorption capabilities for $\mathrm{CH}_{4}, \mathrm{O}_{2}, \mathrm{H}_{2} \mathrm{O}$ and $\mathrm{CO}_{2}$;

Since the partial oxidation of methane is a mildly exothermic reaction and diluted feed is used, the assumption of an isothermal reactor is reasonable (Jin et al., 2000).

Partial oxidation of methane involves one nonreversible reaction and two reversible reactions, which were thoroughly studied by Arai, Yamada and Eguchi (1986), Ross \& Steel (1973), Richardson and Paripatydar (1990) and Xu and Froment (1989).
Fernandes, Souza and Sousa et al. Modeling of Partial ...

$$
\begin{aligned}
& \mathrm{CH}_{4}+\mathrm{O}_{2} \rightarrow \mathrm{CO}_{2}+2 \mathrm{H}_{2} \mathrm{O} \\
& \mathrm{CH}_{4}+\mathrm{H}_{2} \mathrm{O} \leftrightarrow \mathrm{CO}+3 \mathrm{H}_{2} \\
& \mathrm{CH}_{4}+\mathrm{CO}_{2} \leftrightarrow 2 \mathrm{CO}+2 \mathrm{H}_{2}
\end{aligned}
$$

The kinetic model for the reaction on a $\mathrm{Ni} / \mathrm{Al}_{2} \mathrm{O}_{3}$ catalyst is based on a Langmuir-Hinshelwood reaction mechanism which rate expressions for reactions (1) to (3) are given by:

$$
\begin{aligned}
& R_{1}=\frac{k_{1} \cdot P_{\mathrm{CH} 4} \cdot P_{\mathrm{O} 2}^{0.5}}{\left(1+K_{\mathrm{CH} 4} \cdot P_{\mathrm{CH} 4}+K_{\mathrm{O} 2} \cdot P_{\mathrm{O} 2}\right)^{2}} \\
& R_{2}=k_{2} \cdot P_{\mathrm{CH} 4} \cdot P_{\mathrm{H} 2 \mathrm{O}} \cdot\left(1-\frac{P_{\mathrm{CO}} \cdot P_{\mathrm{H} 2}^{3}}{K_{2} \cdot P_{\mathrm{CH} 4} \cdot P_{\mathrm{H} 2 \mathrm{O}}}\right) \\
& R_{3}=k_{3} \cdot P_{\mathrm{CH} 4} \cdot P_{\mathrm{CO} 2} \cdot\left(1-\frac{P_{\mathrm{CO} 2}^{2} \cdot P_{\mathrm{H} 2}^{2}}{K_{3} \cdot P_{\mathrm{CH} 4} \cdot P_{\mathrm{CO} 2}}\right)
\end{aligned}
$$

The changes on the components $\mathrm{CH}_{4}, \mathrm{CO}, \mathrm{H}_{2}, \mathrm{CO}_{2}$ and $\mathrm{H}_{2} \mathrm{O}$ along the reactor length are given by:

$$
\frac{d F_{i}}{d z}=\rho_{b} \cdot A \cdot \sum_{j} v_{i j} \cdot R_{j}
$$

The changes on the component $\mathrm{O}_{2}$ along the reactor length are given by:

$$
\frac{d F_{O 2}}{d z}=\rho_{b} \cdot A \cdot\left(-2 \cdot R_{1}\right)+2 \pi \cdot r_{M} \cdot F_{M}
$$

Oxygen permeation was calculated based on the permeation of a $\mathrm{La}_{0.6} \mathrm{Sr}_{0.3} \mathrm{Co}_{0.2} \mathrm{Fe}_{0.8} \mathrm{O}_{3}$ membrane described by Jin et al. (2000) who correlated the permeation to oxygen partial pressure and temperature.

$$
\begin{aligned}
& F_{M}=\left(9.77 \cdot 10^{-6} \cdot T+1.37 \cdot 10^{-8} \cdot T^{2}\right) \\
& {\left[\begin{array}{l}
\left(P_{O 2}^{R Z} \cdot 10^{-5}\right)^{-\left(2.26 \cdot 10^{-3}+1.62 \cdot 10^{-5} \cdot T\right)}- \\
\left(P_{O 2}^{A Z} \cdot 10^{-5}\right)^{\left(2.26 \cdot 10^{-3}+1.62 \cdot 10^{-5} \cdot T\right)}-0.044
\end{array}\right]}
\end{aligned}
$$

The kinetic parameters for the reaction are presented in Table 1. The simulated operating conditions are presented in Table 2 .

Table 1. Kinetic parameters for partial oxidation of methane.

\begin{tabular}{|c|c|c|}
\hline Parameter & Pre-Exponential Factor & $\begin{array}{c}\text { Ea or } \Delta \mathrm{H} \\
{[\mathrm{J} / \mathrm{mol}]}\end{array}$ \\
\hline $\mathrm{k}_{1}$ & $1.10\left[\mathrm{~mol} / \mathrm{s} \cdot \mathrm{g}_{\mathrm{cat}} \cdot \mathrm{Pa}^{1.5}\right]$ & 166000 \\
$\mathrm{k}_{2}$ & $4.19 \times 10^{-9}\left[\mathrm{~mol} / \mathrm{s}_{\mathrm{cat}} \cdot \mathrm{Pa}^{2}\right]$ & 29000 \\
$\mathrm{k}_{3}$ & $2.42 \times 10^{-9}\left[\mathrm{~mol} /{\left.\mathrm{s} \cdot \mathrm{g}_{\mathrm{cat}} \cdot \mathrm{Pa}^{2}\right]}^{23700}\right.$ & 23700 \\
$\mathrm{~K}_{\mathrm{CH} 4}$ & $6.65 \times 10^{-4}\left[\mathrm{~Pa}^{-1}\right]$ & 103500 \\
$\mathrm{~K}_{\mathrm{O} 2}$ & $1.77 \times 10^{5}\left[\mathrm{~Pa}^{-0.5}\right]$ & 66200 \\
\hline
\end{tabular}


Table 2. Operating conditions and reactor parameters.

\begin{tabular}{|l|c|}
\hline Methane flow rate $[\mathrm{mol} / \mathrm{h}]$ & 5200.0 \\
Total Pressure [atm] & 1.0 \\
Catalyst Density $\left[\mathrm{g}_{\text {cat }} / \mathrm{m}^{3}\right]$ & 2355.2 \\
Bed Porosity & 0.30 \\
Reactor Length [m] & 20.0 \\
Tube internal radius [m] & 0.1016 \\
Tube external radius [m] & 0.1322 \\
Membrane external radius [m] & 0.1500 \\
Membrane thickness [m] & 0.0150 \\
\hline
\end{tabular}

The differential equations 7 and 8 were solved by numerical integration using a $5^{\text {th }}$ order Runge-Kutta-Gill method.

The kinetic data were obtained by $\mathrm{Xu} \&$ Froment (1989) and validated for a fixed bed reactor by Tsai et al. (1997), which has studied this reaction over the entire range of temperature and pressure employed in the present study. The oxygen permeation rate through the membrane was studied and validated by Jin et al. (2000) over the range of temperature $\mathrm{T}=1000$ to $1200 \mathrm{~K}$ at pressure of $\mathrm{P}=1 \mathrm{~atm}$. The computational program used in the present study was tested with the data presented by Tsai et al. (1997) over a traditional fixed bed reactor and the data presented by Jin et al. (2000) was used to test the membrane reactor program and the responses of the membrane. After validation with literature data, the model was used to simulate industrial like conditions for syngas production.

\section{RESULTS AND DISCUSSION}

The major advantage of the membrane reactor is to spread the combustion of methane throughout the reactor length not letting the combustion occur solely at the beginning of the reactor what could damage the reactor due to the amount of heat released by the reaction. Using a membrane, the oxygen is fed continuously through the reactor giving an almost linear consumption of methane (Figs. 2 to 4 ).

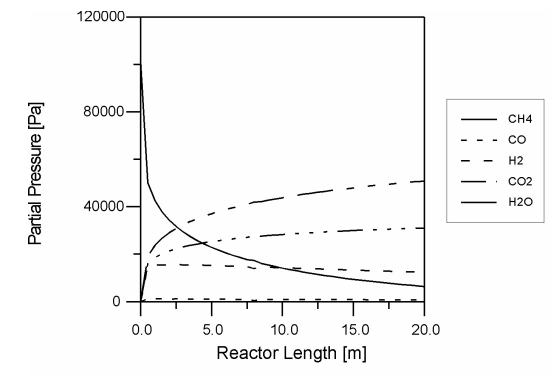

(a)

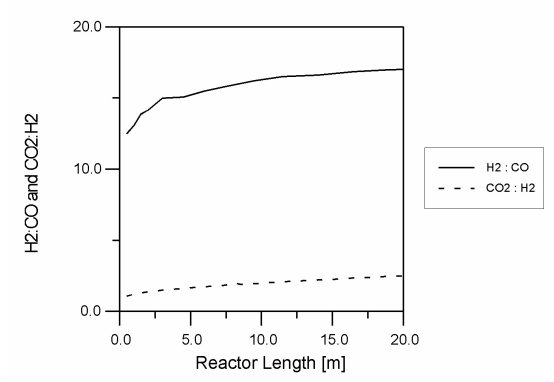

(b)

Fig. 2. Partial pressure (a), and $\mathrm{H}_{2}: \mathrm{CO}$ ratio and $\mathrm{CO}_{2}: \mathrm{H}_{2}$ ratio (b) for membrane reactor operating at isothermal conditions as function of the reactor length $(\mathrm{T}=1173 \mathrm{~K}$, $\left.\mathrm{F}_{\mathrm{CH} 4}{ }^{0}=0.50 \mathrm{~mol} / \mathrm{s}\right)$.
The production of carbon dioxide is considerable due to the combustion of methane. Steam and carbon dioxide reforming are responsible for the formation of syngas, which occurs only to a certain extent, and the reaction selectivity to carbon monoxide is low.

A maximum production of hydrogen is obtained around a conversion of methane of 40 to $60 \%$, depending on reaction temperature, after which the equilibrium of the reactions (2) and (3) take a major shift towards the reactants reducing the amount of hydrogen and carbon monoxide in the reactor. So, the partial oxidation of methane should not proceed to its completion (total consumption of methane). At a methane conversion of $90 \%$ the shift towards the production of $\mathrm{CO}_{2}$ and $\mathrm{H}_{2} \mathrm{O}$ is especially high and the amount of $\mathrm{H}_{2}$ and $\mathrm{CO}$ in the reaction decreases rapidly. The $\mathrm{H}_{2} / \mathrm{CO}$ ratio is high and tends to increase as the reaction proceeds up to a methane conversion of $90 \%$ when these products tend to be consumed by the equilibrium reactions (Fig. 2 b to $4 b$ ).

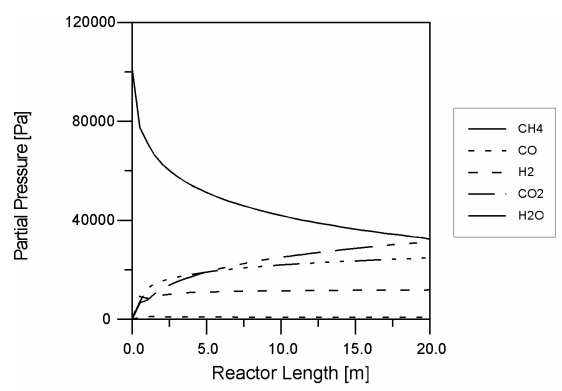

(a)

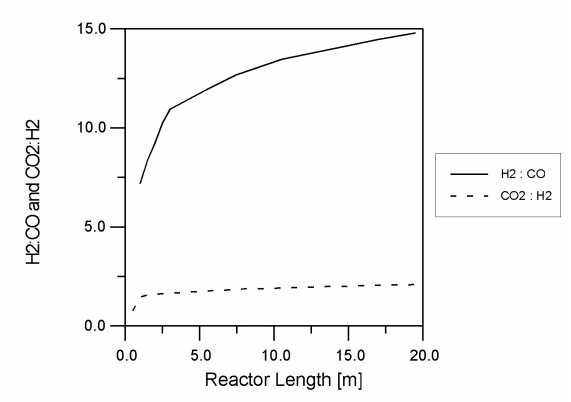

(b)

Fig. 3. Partial pressure (a), and $\mathrm{H}_{2}: \mathrm{CO}$ ratio and $\mathrm{CO}_{2}: \mathrm{H}_{2}$ ratio (b) for membrane reactor operating at isothermal conditions as function of the reactor length $(\mathrm{T}=1123 \mathrm{~K}$,

$$
\left.\mathrm{F}_{\mathrm{CH} 4}{ }^{0}=0.50 \mathrm{~mol} / \mathrm{s}\right) \text {. }
$$

\section{Influence of Temperature}

Temperature plays an important role in partial oxidation of methane both in the conversion of methane and in the $\mathrm{H}_{2}$ : $\mathrm{CO}$ ratio. As the temperature increases, the conversion of methane also increases, and for temperatures above $1250 \mathrm{~K}$, the conversion of methane is total even for high gas loads (Fig. 4a). Below $1000 \mathrm{~K}$, the conversion per pass is very low and product recycling is needed.

The effect of temperature on the $\mathrm{H}_{2}$ : $\mathrm{CO}$ ratio is complex but it decreases when temperature increases, so higher temperatures favors lower $\mathrm{H}_{2}$ : $\mathrm{CO}$ ratios which can be needed for processes such as the Fischer-Tropsch synthesis (Fig. 4b), which requires $\mathrm{H}_{2} / \mathrm{CO}$ ratios near 2:1. Any way, pos processing of the syngas is required in order to remove the excess of hydrogen in the syngas if it is to be used in Fischer-Tropsch synthesis. 


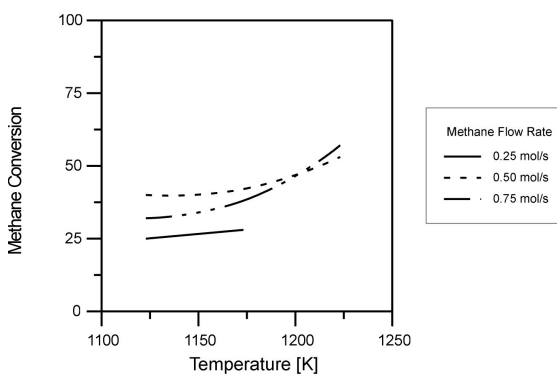

(a)

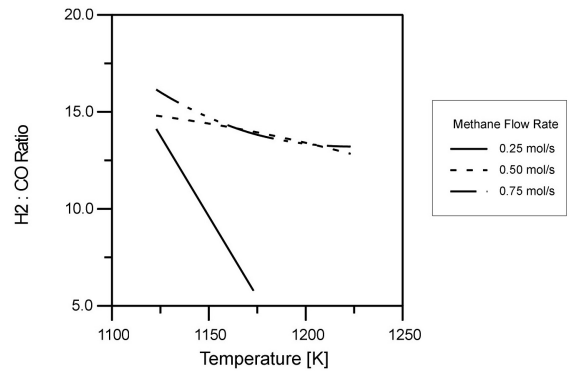

(b)

Fig. 4. Methane conversion (a) and $\mathrm{H}_{2} / \mathrm{CO}$ ratio (b) for a membrane reactor as function of temperature and gas load.

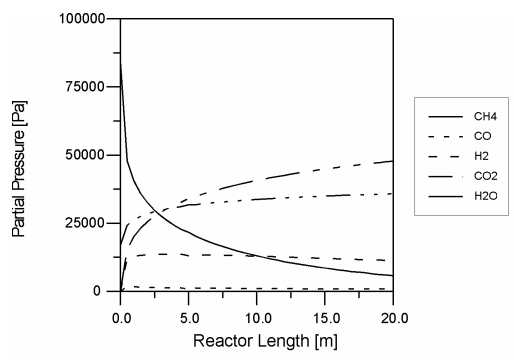

(a)

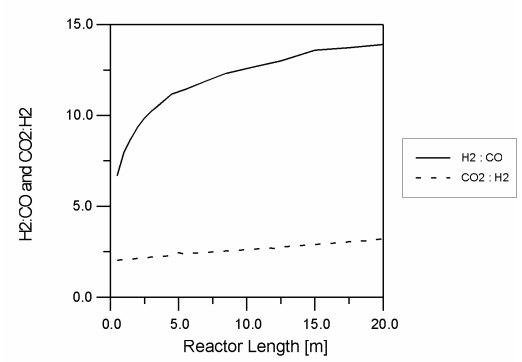

(b)

Fig. 5. Partial pressure (a), $\mathrm{H}_{2}: \mathrm{CO}$ ratio and $\mathrm{CO}_{2}: \mathrm{H}_{2}$ ratio (b) for membrane reactor operating at isothermal conditions as function of the reactor length $(\mathrm{T}=1223 \mathrm{~K}$, $\left.\mathrm{F}_{\mathrm{CH} 4}{ }^{0}=0.50 \mathrm{~mol} / \mathrm{s}\right)$. Initial flow rate of $\mathrm{CO}_{2}=0.2 \mathrm{CH}_{4}$ flow rate.

\section{Influence of $\mathrm{CH}_{4} / \mathrm{CO}_{2}$ ratio}

Carbon dioxide reforming usually proceeds in the presence of an excess of carbon dioxide to enhance reforming. The effect of molar carbon dioxide-to-methane $\left(\mathrm{CO}_{2} / \mathrm{CH}_{4}\right)$ ratio was examined by varying this ratio from 0.2 to 0.6. Partial pressure profiles for the reaction for two different $\mathrm{CO}_{2} / \mathrm{CH}_{4}$ ratios are shown in Figs. 5 and 6 , and results for three different temperatures are shown in Fig 7.

Recycling the $\mathrm{CO}_{2}$ produced by the combustion reaction and not converted to syngas back to the reactor feed can enhance the production of syngas shifting the carbon dioxide reforming towards the production of syngas. Higher amounts of carbon dioxide in the reactor help to lower the $\mathrm{H}_{2} / \mathrm{CO}$ ratio and the amount of syngas produced is also higher.

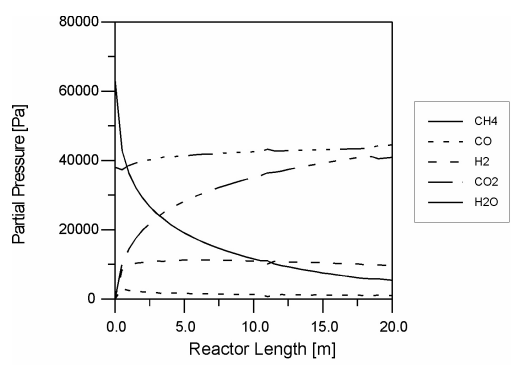

(a)

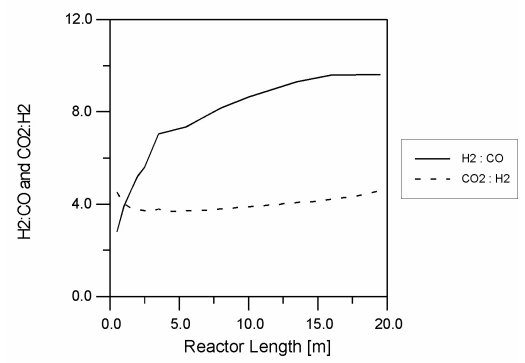

(b)

Fig. 6. Partial pressure (a), $\mathrm{H}_{2}: \mathrm{CO}$ ratio and $\mathrm{CO}_{2}: \mathrm{H}_{2}$ ratio (b) for membrane reactor operating at isothermal conditions as function of the reactor length $(\mathrm{T}=1223 \mathrm{~K}$, $\mathrm{F}_{\mathrm{CH} 4}{ }^{0}=0.50 \mathrm{~mol} / \mathrm{s}$ ). Initial flow rate of $\mathrm{CO}_{2}=0.6 \mathrm{CH}_{4}$ flow rate.

\section{Influence of $\mathrm{CH}_{4} / \mathrm{H}_{2} \mathrm{O}$ ratio}

Steam reforming usually proceeds in the presence of an excess of steam to enhance reforming and syngas production. The effect of molar steam-to-methane $\left(\mathrm{H}_{2} \mathrm{O} / \mathrm{CH}_{4}\right)$ ratio was examined by varying this ratio from 0.2 to 0.6 . Partial pressure profiles for the reaction for a $\mathrm{H}_{2} \mathrm{O} / \mathrm{CH}_{4}$ ratio is shown in Figs. 8, and results for three different temperatures are shown in Fig 9. Adding steam to the reactor feed can enhance the production of syngas shifting the steam reforming towards the production of syngas, but at the expense of a higher $\mathrm{H}_{2} / \mathrm{CO}$ ratio which can be undesirable for GTL processes.

\section{Influence of membrane permeability}

Membrane permeability is directly related to the flow rate of oxygen from the air stream zone to the reaction zone and therefore influences the rate of methane combustion. Total conversion of methane increases as the oxygen flow rate through the membrane increases, due to the greater amount of oxygen available to the reaction (Fig 10). Temperature inside the reaction zone is directly affected by the highly exothermic combustion reaction and temperature control can be attained by controlling the amount of oxygen that can flow to the reaction zone.

Lower oxygen partial pressure inside the air zone can lower the oxygen flow rate to the reaction zone, as well as, the use of membranes that allows the flow of a limited amount of oxygen to the reaction zone. In the latter case the membrane should be chosen during the project of the reactor and can be used as to set a maximum permeability for the system. 

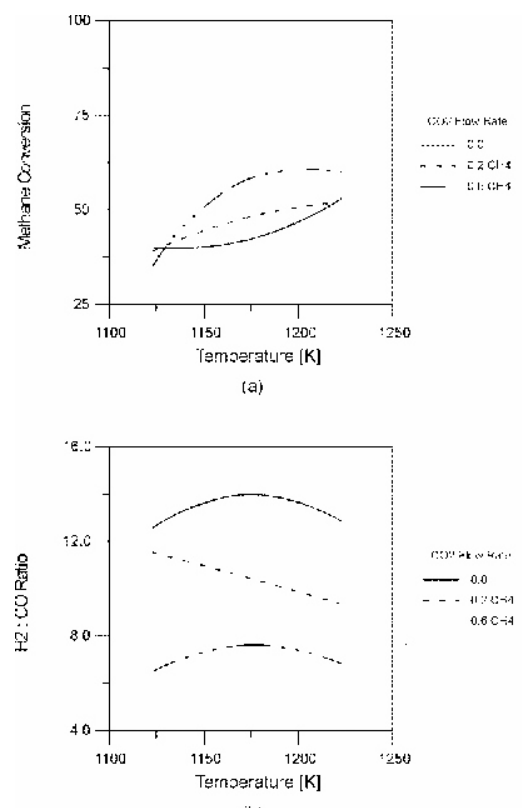

(bi)

Fig. 7. Methane conversion (a) and $\mathrm{H}_{2} / \mathrm{CO}$ ratio (b) for a membrane reactor as function of temperature and carbon dioxide flow rate at the maximum hydrogen production point.

\section{Controlling the $\mathrm{H}_{2} / \mathrm{CO}$ Ratio}

Controlling the $\mathrm{H}_{2} / \mathrm{CO}$ ratio is important, especially to gas-to-liquid processes (GTL) where the optimum ratio varies from 0.7 up to 3.0, and influences hydrocarbon product distribution. In partial oxidation of methane, the $\mathrm{H}_{2} / \mathrm{CO}$ ratio is large and lowering this ratio would require operating in high temperatures, which gives the lowest $\mathrm{H}_{2} / \mathrm{CO}$ ratio. Even so, the ratio remains very high for use in GTL process and further processing is required to control the $\mathrm{H}_{2} / \mathrm{CO}$ ratio. An option is to pass the crude syngas through a membrane absorption unit so hydrogen can permeate through the membrane correcting the $\mathrm{H}_{2} / \mathrm{CO}$ ratio to the desired level. The membrane absorption unit can be shaped as a multitube heat exchanger where the syngas passes through the inner or outer side of the membrane tubes. Hydrogen permeates from the syngas towards the hydrogen-poor sweep gas adjusting the $\mathrm{H}_{2} / \mathrm{CO}$ ratio to a desired value.

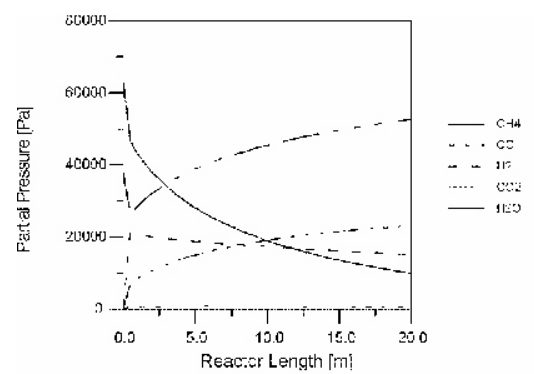

(a)

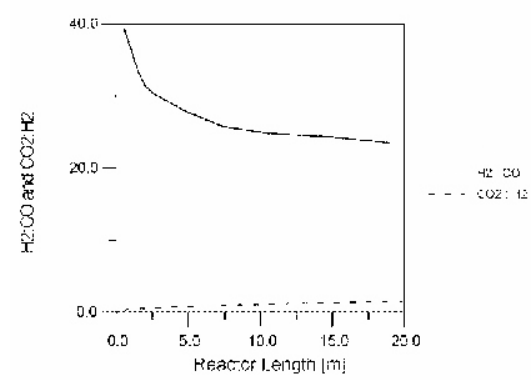

(b)
Fernandes, Souza and Sousa et al. Modeling of Partial ...

Fig. 8. Partial pressure (a), $\mathrm{H}_{2}: \mathrm{CO}$ ratio and $\mathrm{CO}_{2}: \mathrm{H}_{2}$ ratio

(b) for membrane reactor operating at isothermal conditions as function of the reactor length $(\mathrm{T}=1173 \mathrm{~K}$, $\left.\mathrm{F}_{\mathrm{CH} 4}{ }^{0}=0.50 \mathrm{~mol} / \mathrm{s}\right)$. Initial flow rate of $\mathrm{H}_{2} \mathrm{O}=0.6 \mathrm{CH}_{4}$
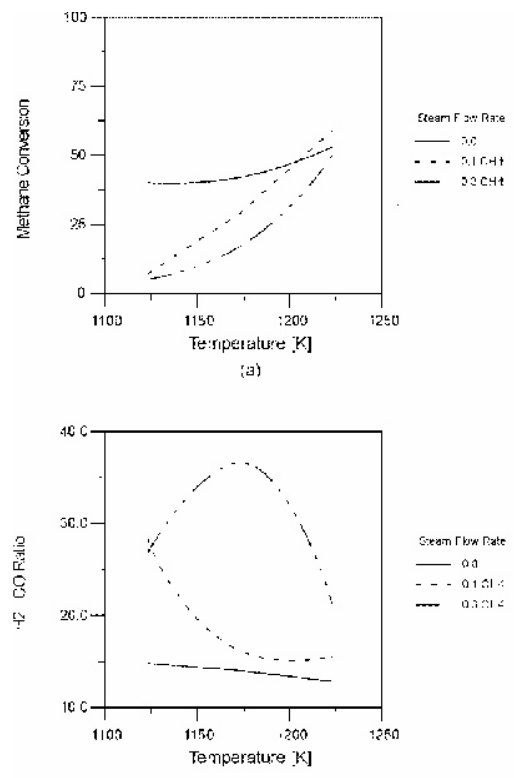

(b)

Fig. 9. Methane conversion (a) and $\mathrm{H}_{2} / \mathrm{CO}$ ratio (b) for a membrane reactor as function of temperature and steam flow rate at the maximum hydrogen production point.

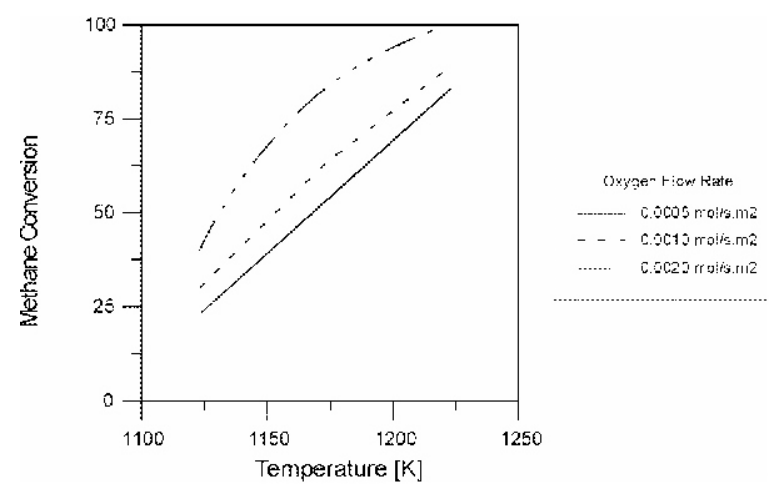

Fig. 10. Methane conversion for a membrane reactor as function of temperature and oxygen flow rate through the membrane (conversion at reactor length $=20 \mathrm{~m}$ ).

\section{CONCLUSIONS}

The partial oxidation of methane was studied from a modeling point of view in a membrane reactor. Simulation results show that different parameters affect methane conversion and $\mathrm{H}_{2} / \mathrm{CO}$ ratio, such as temperature, molar flow rate, steam and carbon dioxide recycling. Enhanced conversion of methane to syngas can be attained by recycling carbon dioxide and steam back to the reactor entrance as to shift the equilibrium reactions towards syngas. As such, the membrane reactors are a good alternative to produce syngas for GTL processes or pure hydrogen. Operating conditions can be set to control the $\mathrm{H}_{2} / \mathrm{CO}$ ratio to a desired value, removing $\mathrm{H}_{2}$ through the membrane. New simulations are needed to optimize the reactor and to study the reaction in multiple steps changing the temperature of each step as to produce a greater quantity of syngas and to reduce the amount of gas that has to be recycled. 


\section{ACKNOWLEDGEMENTS}

The authors gratefully acknowledge the financial support of the Brazilian research funding institution CNPq-CTPetro.

\section{REFERENCES}

Arai, H., Yamada, T., and Eguchi, K., 1986, Catalytic combustion of methane over various perovskite-type oxides. Applied Catalisys, Vol. 26, pp. 265-276.

Ashcroft, A.T., Cheetham, A.K., Foord, J.S., Green, M.L.H., Grey, C.P.J., Murrell, A., and Vernon, P.D.F., 1990, Selective oxidation of methane to synthesis gas using transition metal catalysis. Nature, Vol. 344, pp. 319321.

Assaf, E.M., Jesus, C.D.F. and Assaf, J.M., 1998, Mathematical modelling of methane steam reforming in a membrane reactor: an isothermic model. Brazilian Journal of Chemical Engineering, Vol. 15, pp. 160-166.

Balachandran, U., Dusek, J.T., Maiya, P.S., Ma, B., Mieville, R.L., Kleefish, M.S., and Udovich, C.A., 1997, Ceramic membrane reactor for converting methane to syngas. Catalysis Today, Vol. 36, pp. 265-272.

Chen, Z., Prasad, P., Yan, Y., and Elnashaie, S., 2003, Simulation for steam reforming of natural gas with oxygen input in a novel membrane reformer. Fuel Processing Technology, Vol. 83, pp. 235-252.

Choudhary, V.R., Rajput, A.M., and Prabhakar, B., 1992, Low temperature oxidative conversion of methane to syngas over NiO-CaO catalyst. Catalysis Letters, Vol. 15, pp. 363-370.

Dissanayake, D., Rosynek, M.P., Kharas, K.C.C, and Lunsford, J.H., 1991, Partial oxidation of methane to carbon monoxide and hydrogen over a Ni/ $/ \mathrm{Al}_{2} \mathrm{O}_{3}$ catalyst. Journal of Catalysis, Vol. 132,pp. 117-127.

Gallucci, F., Paturzo, L., and Basile, A., 2004, A simulation study of the steam reforming of methane in a dense tubular membrane reactor. International Journal of Hydrogen Energy, Vol. 29, pp. 611-617.

Hickman, D.A., and Schmidt, L.D., 1993, Steps in $\mathrm{CH}_{4}$ oxidation on Pt and Rh sufaces: high temperature reactor simulations. AIChE Journal, Vol. 39, pp. 1164-177.

Jin, W., Gu, X., Li, S., Huang, P., Xu, N., and Shi, J., 2000, Experimental and simulation study on a catalyst packed tubular dense membrane reactor for partial oxidation of methane to syngas. Chemical Engineering Science, Vol. 55, pp. 2617-2625.

Kao, Y.K., Lei, L., and Lin, Y.S., 1997, A comparative simulation study on the oxidative coupling of methane in fixed-bed and membrane reactors. Industrial and Engineering Chemistry Research, Vol. 36, pp. 3583-3593.

Lin, Y.M., Liu, S.L., Chuang, C.H., and Chu, Y.T., 2003, Effect of incipient removal of hydrogen throuth palladium membrane on the conversion of methane steam reforming. Experimental and modeling. Catalysis Today, Vol. 82, pp. 127-139.

Richardson, J.T., and Paripatydar, S.A., 1990, Carbon dioxide reforming of methane with supported rhodium. Applied Catalisys, Vol. 61,pp. 293-309.

Ross, J.R.H., and Steel, M.C.F.J., 1973, Mechanism of steam reforming of methane over a coprecipitated Nickel - alumina catalyst. Chemical Society Faraday Transactions, Vol. 69, pp. 10-21.

Shu, J., Grandjean, B.P.A., and Kaliaguine, S., 1994, Methane steam reforming in asymmetric Pd and Pd$\mathrm{Ag} /$ Porous SS membrane reactors. Applied Catalysis A, Vol. 119, pp. 305-325.

Engenharia Térmica (Thermal Engineering), Vol. 5 - No 01 - July 2006
Tsai, C.Y., Dixon, A.G., Moser, W.R., and Ma, Y.H., 1997, Dense perovskite membrane reactors for the partial oxidation of methane to syngas. AIChE Journal, Vol. 43, pp. 2741-2750.

Wang, W., and Lin, Y.S., 1995, Analysis of oxidative coupling of methane in dense membrane reactors. Journal of Membrane Science, Vol. 103, pp. 219-233.

Xu, J., and Froment, G.F., 1989, Methane steam reforming, methanation and water gas shift: I. Intrinsic kinetics. AIChE Journal, Vol. 35, pp. 88-96. 